\title{
Does Bilateral ITA Grafting Increase Perioperative Complications? Outcome of 6,476 Patients with Bilateral versus 5,020 Patients with Single ITA Bypass
}

\author{
Oliver Deutsch ${ }^{1, *}$ Laura Gansera ${ }^{2, *}$ Markus Wunderlich ${ }^{1} \quad$ Walter Eichinger $^{1} \quad$ Brigitte Gansera ${ }^{1}$
}

${ }^{1}$ Department of Cardiovascular Surgery, Klinikum Bogenhausen, Munich, Germany

2 Department of Cardiology, Klinikum Augsburg, Augsburg, Germany

${ }^{*}$ Both authors contributed equally to the work.
Address for correspondence Brigitte Gansera, MD, PhD, Department of Cardiovascular Surgery, Klinikum Bogenhausen, Englschalkingerstrasse 77, Munich 81925, Germany (e-mail: brigitte_gansera@web.de).

Thorac Cardiovasc Surg 2016;64:188-194.

\begin{abstract}
Objectives Despite the superior patency of internal thoracic artery (ITA) grafting compared with saphenous veins, frequency of bilateral ITA (BITA) grafting in Europe is still approximately $10 \%$. The aim of the present study was to compare the early outcome of patients receiving either BITA or single ITA (SITA) grafting.

Methods A total of 11,496 patients with isolated coronary artery bypass grafting (CABG), operated between January 1996 and December 2012, were analyzed retrospectively; 0.6476 patients (mean age 65.2 years, $81.3 \%$ males) received BITA and 5,020 patients (mean age 66.6 years, $76.7 \%$ males) SITA grafting. Mean body mass index (BMI) was 27.2 versus $27.4, p=0.017$. Incidence of diabetes was 28.9 versus $28.4 \%, p=0.08$. Ejection fraction (EF) $>50$ was $71.3 \%$ (BITA) versus $66.3 \%$ (SITA), $p<0.001$. Elective operations were performed in $88.4 \%$ (BITA) versus $83.3 \%$ (SITA), and urgent/emergent surgery was necessary in $11.6 \%$ (BITA) versus $16.7 \%$ (SITA), $p<0.001$.

Results Number of grafts was 3.76 (BITA) versus 3.06, $p<0.001$. Duration of surgery (194.4 vs. 180.4 minutes) as well as X-clamp time (60.4 vs. 51.7 minutes) was prolonged for BITA, $p<0.001$. Perioperative infarction rate revealed 3.2\% (BITA) versus $3.6 \%$, $p=0.54$. Frequency of rethoracotomy due to bleeding was higher in the BITA group (3.8 vs. $2.1 \%$ ), $p<0.001$. Sternal instabilities occurred in $2.3 \%$ (BITA) versus $2.2 \%$, $p=0.749$. Duration of mechanical ventilation $<12$ hours was 74.6 versus $77.1 \%$, $p=0.09$ and duration of in-hospital stay was 10.5 versus 10.4 days, $p=0.68$. Thirty-day mortality was $2.4 \%$ (BITA) versus $3.0 \%, p=0.09$. Multivariate analysis identified prolonged duration of surgery, BMI $>30$, emergent operations, advanced age, and BITA grafting as predictor for sternal instabilities. EF $<30 \%$, advanced age plus emergency were associated with increased 30-day mortality.

Keywords

- bilateral ITA

- outcome

Conclusion CABG using BITA can be performed routinely with good clinical results and low mortality. Compared with SITA grafting, bleeding complications were enhanced.
\end{abstract}

received

February 23, 2015

accepted after revision

May 29, 2015

published online

August 13, 2015 (c) 2016 Georg Thieme Verlag KG

Stuttgart · New York
DOI http://dx.doi.org/ 10.1055/s-0035-1558992. ISSN 0171-6425. 


\section{Introduction}

Coronary artery bypass grafting (CABG) with bilateral internal thoracic artery (ITA) (BITA) grafting can improve longterm results in cardiac morbidity and mortality. Numerous clinical investigations could demonstrate an evident benefit in survival for BITA compared to single ITA (SITA) grafting. ${ }^{1-3}$ An enhanced incidence of bleeding and wound complications, compared with patients with SITA remains an ongoing debate. Particularly, in patients suffering from diabetes, pedicled harvest of both ITAs is described to increase the risk of postoperative deep sternal wound infections. ${ }^{4}$ In contrary, other series, even including small patients cohorts, did not identify pedicled BITA harvesting as a risk factor for mediasinitis. ${ }^{5}$ The aim of the study was to compare the postoperative outcomes (30 days) in a large cohort of patients who had undergone CABG with BITA or SITA in situ or T-grafts, especially to identify patient-related risk factors, such as obesity and advanced age.

\section{Methods}

A total of 11,496 patients with isolated CABG, operated between January 1996 and December 2012, were analyzed retrospectively; 6,476 patients (mean age 65.2 years, $81.3 \%$ males) received BITA and 5,020 patients (mean age 66.6 years, $76.7 \%$ males) SITA grafting. Mean body mass index (BMI) was 27.2 versus 27.4, $p=0.017$. Incidence of diabetes mellitus was 28.9 versus $28.4 \%$, $p=0.08$. Ejection fraction $(\mathrm{EF})>50$ was $71.3 \%$ (BITA) versus $66.3 \%$ (SITA), $p<0.001$. Elective operations were performed in $88.4 \%$ (BITA) versus $83.3 \%$ (SITA), and urgent/emergent surgery was necessary in $11.6 \%$ (BITA) versus $16.7 \%$ (SITA), $p<0.001$. Patients who were under preoperative resuscitation were excluded from the study.

\section{Statistical Analysis}

Demographic and clinical data are presented as frequency distribution and simple percentages. Values of continuous variables are expressed as mean \pm standard deviation. In unmatched patient cohorts, univariate analysis of selected preoperative and postoperative discrete variables was accomplished by the chi-square test with the appropriate degrees of freedom or the Fishers exact test to assess the equality of proportions. Conditional logistic regression models with ordinal variables were used to determine the independent effects of selected demographic/clinical variables on hospital complications and mortality. All analyses were performed with SPSS (Statistical Package for Social Science version 18, SPSS Inc., Chicago, Illinois). A $p$-value $<0.05$ was considered to indicate statistical significance.

\section{Results}

Demographic data are depicted in -Table 1. Operative data are depicted in $\mathbf{- T a b l e ~ 2}$. Perioperative complications and mortality are depicted in $\mathbf{- T a b l e ~} \mathbf{3}$. The multivariate regression analysis for variables influencing complications and mortality is given in $\boldsymbol{-}$ Table $\mathbf{4}$. - Table $\mathbf{5}$ shows a division of sternal instabilities related to the surgical ITA-harvesting approach (pedicled or skeletonized), different graft technique (in situ or T-graft) in dependence of diabetes/no diabetes. Number of grafts was higher in the BITA group, as well as duration of surgery and X-clamp time was prolonged for BITA grafting. Perioperative infarction rate revealed no statistical significant difference between both groups. Frequency of rethoracotomy due to bleeding was significantly higher in the BITA group. Sternal instabilities occurred in 2.3\% (BITA) versus $2.2 \%$ (SITA), $p=0.749$. Sternal instabilities without

Table 1 Demographic data and preoperative variables

\begin{tabular}{|c|c|c|c|}
\hline Variables & SITA & BITA & $p$-Value \\
\hline Patients, $n(\%)$ & $5,020(100.0)$ & $6,476(100.0)$ & \\
\hline \multicolumn{4}{|l|}{ Sex, $n(\%)$} \\
\hline Male & $3,850(76.7)$ & $5,265(81.3)$ & \multirow[t]{2}{*}{$<0.001$} \\
\hline Female & $1,170(23.3)$ & $1,211(18.7)$ & \\
\hline Age, mean $\pm S D, y$ & $66.6 \pm 9.2$ & $65.2 \pm 9.3$ & $<0.001$ \\
\hline Body mass index, mean \pm SD & $27.4 \pm 5.2$ & $27.2 \pm 3.2$ & 0.017 \\
\hline \multicolumn{4}{|l|}{$\mathrm{EF}(\%)$} \\
\hline$E F>50 \%$ & $66.3 \%$ & $71.3 \%$ & \multirow[t]{3}{*}{$<0.001$} \\
\hline EF $30-50 \%$ & $28.8 \%$ & $24.7 \%$ & \\
\hline$E F<30 \%$ & $4.9 \%$ & $4.1 \%$ & \\
\hline \multicolumn{4}{|c|}{ Elective/urgent/emergent operation } \\
\hline Elective (\%) & 83.3 & 88.4 & \multirow[t]{3}{*}{$<0.001$} \\
\hline Urgent (\%) & 9.6 & 6.3 & \\
\hline Emergent (\%) & 7.8 & 5.2 & \\
\hline
\end{tabular}

Abbreviations: BITA, bilateral internal thoracic artery; EF, ejection fraction; SD, standard deviation; SITA, single internal thoracic artery. 
Table 2 Comparison of operative data

\begin{tabular}{|l|l|l|l|}
\hline Variables & SITA & BITA & $p$-Value \\
\hline Number of grafts (mean \pm SD) & $3.06 \pm 0.92$ & $3.76 \pm 0.92$ & $<0.0001$ \\
\hline Duration of surgery (min, mean) & $180.4 \pm 55.8$ & $194.4 \pm 48.5$ & $<0.0001$ \\
\hline Bypass time (min, mean) & $79.8 \pm 33.5$ & $84.8 \pm 28.3$ & $<0.0001$ \\
\hline X-clamp time (min, mean) & $51.7 \pm 22.2$ & $60.4 \pm 18.9$ & $<0.001$ \\
\hline
\end{tabular}

Abbreviations: BITA, bilateral internal thoracic artery; SD, standard deviation; SITA, single internal thoracic artery.

infection were $0.6 \%$ (SITA) versus $1.0 \%$ (BITA), $p=0.03$, but incidence of sternal instabilities with infection was lower in the BITA group, $1.6 \%$ (SITA) versus $1.3 \%$ (BITA), $p=0.26$. Division of sternal instabilities related to the surgical ITAharvesting approach (pedicled or skeletonized) and different graft technique (in situ or T-graft) result in a comparable incidence for patients with or without diabetes in the pedicled SITA in situ group ( 2.9 vs. $2.8 \%, p=0.838$ ); but in a higher incidence of sternal complications in patients with diabetes of the pedicled in situ BITA group ( 0.9 vs. $2.4 \%, p=0.001$ ). In patients receiving skeletonized SITA grafts $(n=827$ of all 5,020 SITAs), or skeletonized BITA T-grafts $(n=263$ of all 6,476 BITAs), sternal instabilities occur in a higher frequency compared with the former group, but without statistical differences between patients suffering from diabetes or not.

Duration of mechanical ventilation $<12$ and $>24$ hours were comparable between the groups. Mean period of inhospital stay was 10.5 versus 10.4 days. Thirty-day mortality was higher in the SITA group, without statistically significance. Multivariate analysis identified prolonged duration of surgery, BMI $>30$, advanced age, and BITA grafting as predictors for sternal instabilities without infections. Sternal wound infections were strongly associated with prolonged duration of cardiopulmonary bypass. $\mathrm{EF}<30 \%$, advanced age, emergent operations, duration of surgery, bypass, and X-clamp time were independent predictors for increased 30-day mortality.

\section{Discussion}

Multiple cohort studies have demonstrated that long-term outcome after CABG can be improved remarkably when both ITAs are used for revascularization. ${ }^{1,3,6-8}$ There is evidence about superior patency of ITA grafting to saphenous veins. ${ }^{9}$ The use of the left ITA bypass preferentially to the left anterior descending artery (LAD) has become surgical standard, providing reduced cardiac events, and enhanced survival rates, compared with patients receiving isolated vein grafts. Although the evidence that the long-term outcome after CABG using both ITAs results in convincing beneficial advantages, ${ }^{1,3,6-8}$ the frequency of BITA grafting in Europe is still approximately $10 \% .{ }^{10}$ The National US Database of the Society of Thoracic Surgeons reports that $<4 \%$ of patients, who underwent CABG currently receive the benefits of BITA grafting. ${ }^{11}$ There is an ongoing discussion of pros and cons for this surgical approach. Although there is consensus that BITA grafting can improve long-term survival, ${ }^{3}$ the reluctance to use BITA seems to be based on the fear of deep sternal wound infections, especially among diabetic patients. Some reports describe a higher incidence of wound-healing and bleeding complications after BITA grafting, ${ }^{4,12}$ in particular, when pedicled harvesting is performed in diabetic patients. $^{4,12,13}$ A large series, consisting of 126,235 diabetic patients (122,465 SITA and 3,770 BITA) published by Deo et

Table 3 Comparison of postoperative complications

\begin{tabular}{|l|l|l|l|}
\hline Variables & SITA & BITA & $p$-Value \\
\hline Myocardial infarction (\%) & 3.6 & 3.2 & 0.54 \\
\hline Rethoracotomy due to bleeding (\%) & 2.1 & 3.8 & $<0.001$ \\
\hline Sternal instabilities, all (\%) & 2.2 & 2.3 & 0.749 \\
\hline Sternal instabilities without infection (\%) & 0.6 & 1.0 & 0.03 \\
\hline Sternal instabilities with infection (\%) & 1.6 & 1.3 & 0.26 \\
\hline Mechanical ventilation $<12$ h (\%) & 77.1 & 74.6 & 0.09 \\
\hline Mechanical ventilation $>24$ h (\%) & 8.6 & 3.1 & 0.07 \\
\hline Reintubation (\%) & 3.7 & 0.5 & 0.002 \\
\hline Tracheotomy (5\%) & 0.7 & $10.5 \pm 9.3$ & 0.002 \\
\hline In-hospital stay, d (mean \pm SD) & $10.4 \pm 9.5$ & 2.4 & 0.68 \\
\hline 30-day mortality (\%) & 3.0 & 0.09 \\
\hline
\end{tabular}

Abbreviations: BITA, bilateral internal thoracic artery; SD, standard deviation; SITA, single internal thoracic artery. 
Table 4 Multivariate regression analysis for variables influencing complications and mortality ${ }^{\mathrm{a}}$

\begin{tabular}{|c|c|c|c|}
\hline \multirow[t]{2}{*}{ Variables } & \multirow[t]{2}{*}{$p$-Value } & \multicolumn{2}{|c|}{ 95\% confidence interval } \\
\hline & & Lower bound & Upper bound \\
\hline \multicolumn{4}{|c|}{ Sternal instability with infection } \\
\hline Age & 0.630 & -0.021 & 0.013 \\
\hline $\mathrm{BMI}$ & 0.515 & -0.016 & 0.032 \\
\hline LVEF $<30 \%$ & 0.572 & -1.063 & 0.588647 \\
\hline Emergency & 0.843 & -0.245 & 0.300 \\
\hline Duration of operation & 0.110 & -0.008 & 0.01 \\
\hline Bypass time & 0.032 & 0.001 & 0.020 \\
\hline X-clamp time & 0.810 & -0.015 & 0.012 \\
\hline Use of BITA & 0.317 & -0.160 & 0.493 \\
\hline \multicolumn{4}{|c|}{ Sternal instability without infection } \\
\hline Age & 0.000 & 0.037 & 0.087 \\
\hline $\mathrm{BMI}$ & 0.034 & 0.001 & 0.039 \\
\hline Emergency & 0.026 & 0.040 & 0.624 \\
\hline LVEF $<30 \%$ & 0.065 & -0.042 & 1.418 \\
\hline Duration of operation & 0.000 & 0.004 & 0.012 \\
\hline Bypass time & 0.381 & -0.018 & 0.007 \\
\hline $\mathrm{X}$-clamp time & 0.954 & -0.017 & -0.108 \\
\hline Use of BITA & 0.015 & -1.017 & -0.108 \\
\hline \multicolumn{4}{|l|}{ 30-day survival } \\
\hline Age & 0.000 & -0.066 & -0.037 \\
\hline $\mathrm{BMI}$ & 0.780 & -0.015 & 0.20 \\
\hline Emergency & 0.000 & -0.784 & -0.492 \\
\hline Duration of operation & 0.000 & -0.011 & -0.007 \\
\hline$E F<30 \%$ & 0.000 & 0.779 & 1.502 \\
\hline Bypass time & 0.000 & -0.023 & -0.12 \\
\hline X-clamp time & 0.000 & 0.012 & 0.028 \\
\hline Use of BITA & 0.983 & -0.247 & 0.252 \\
\hline
\end{tabular}

Abbreviations: BITA, bilateral internal thoracic artery; BMI, body mass index; EF, ejection fraction; LVEF, left ventricular ejection fraction; SD, standard deviation.

Note: Bold values show $p$ values $<0.05$.

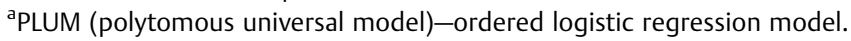

$\mathrm{al}^{4}{ }^{4}$ identified the risk of deep sternal wound infections to be minimized when performing ITA harvesting in a skeletonized manner. With this approach, patients after BITA grafting had a similar risk of deep sternal infections compared with SITA grafting.

A comparison of these results to our own seems to be difficult, as our cohort contributes in only $28 \%$ of patients suffering from diabetes. Nevertheless, incidence of deep wound infection was at least $3.1 \%$ for BITA and $1.6 \%$ for the SITA in the mentioned investigation of $3,770 \mathrm{BITAs},{ }^{4}$ whereas deep sternal wound infection occurred in only $1.3 \%$ of 6,476 BITA grafts in our own series. Moreover, we performed a mixed approach of pedicled harvesting (until the year 2010) and skeletonized technique (since the year 2010); therefore, simple comparison to the results in the literature seems problematic. After the performance of a subgroup analysis within our collective, the use of pedicled BITA harvest did lead to increased sternal wound complication rates than the use of skeletonized BITAs (2.4 vs. 3.3\%), even in diabetic patients (3.9 vs. $5.2 \%$ ).

Nevertheless, patients suffering from diabetes who received pedicled in situ BITA grafts were identified to experience significant higher rates of sternal instabilities compared with those without diabetes ( 3.9 vs. $2.4 \%, p=0.001$ ).

Choo et $\mathrm{al}^{5}$ identified pedicled BITA grafting not to be associated with an increased incidence of infectious sternal complications, albeit in only 162 patients with or without existing diabetes. Randomized clinical trials concerning this issue are rarely available, most of the studies are of observational character or deal with small collectives. Taggart et al ${ }^{12}$ 
Table 5 Sternal wound complications

\begin{tabular}{|c|c|c|c|}
\hline Variables & Diabetes & No diabetes & p-Value \\
\hline \multicolumn{4}{|c|}{ SITA $(n=4,193)$ and BITA $(n=6,213)$, pedicled, in situ grafts $(1996-2010)$, related to diabetes } \\
\hline Sternal instabilities (all) BITA (\%) & $3.9 \%$ & $2.4 \%$ & 0.001 \\
\hline Sternal instabilities (all) SITA (\%) & $2.9 \%$ & $2.8 \%$ & 0.838 \\
\hline \multicolumn{4}{|c|}{ SITA $(n=827)$ and BITA $(n=263)$, skeletonized, T-grafts $(2010-2012)$, related to diabetes } \\
\hline Sternal instabilities (all) BITA (\%) & $5.2 \%$ & $3.4 \%$ & 0.463 \\
\hline Sternal instabilities (all) SITA (\%) & $4.4 \%$ & $4.0 \%$ & 0.852 \\
\hline
\end{tabular}

Abbreviations: BITA, bilateral internal thoracic artery; SITA, single internal thoracic artery.

published the results of the unique randomized investigation, a multicenter study including 1,554 patients with SITA grafting and 1,548 patients with BITA grafting. Perioperative complications as well as results after 1 year were similar between both groups in terms of mortality, infarction rate, and repeated revascularization. A small increase for the need of sternal wound reconstructions was observed ( $0.6 \%$ SITA vs. $1.9 \%$ BITA), around half of these patients had a history of diabetes in comparison with, similar to our portion, around one-quarter of all patients in the whole trial. Advocates of BITA grafting regularly survey larger cohorts than their opponents. One of the most important recently published study concerning this subject was performed by Dorman et $\mathrm{al}^{6}$ : a 30-year follow-up of propensity score-matched cohorts, which consist of diabetic patients receiving either SITA $(n=414)$ or BITA $(n=414)$. This sophisticated and welldone study identified BITA grafting providing enhanced survival without any increase in perioperative morbidity or mortality. Although ITA harvest was performed exclusively in a pedicled manner, incidence of deep sternal infections was nearly similar between SITA and BITA groups. These data are supported by numerous prior investigations. ${ }^{5,14-16}$

Other groups strongly recommend the skeletonized approach to preserve sternal blood flow. ${ }^{4,13,17-19}$ Kamiya et al ${ }^{17}$ could verify in a small collective $(n=24)$ that the damage of the tissue microcirculation in the middle and lower retrosternal area was significantly less after ITA skeletonization compared with that after the pedicled ITA-harvesting technique. In this context, the authors of the present trial would like to emphasize that in case of pedicled ITA harvesting, the pedicle was always kept very small.

Toumpoulis et $\mathrm{al}^{19}$ analyzed 140 articles related to this subject. Twenty four articles were identified to give best evidence. In general, BITA grafting carries a 2.5- to 5-fold higher risk for mediastinitis, which does raise up to $10 \%$ in diabetic patients, but can be reduced to $0.4-2.6 \%$ when skeletonized techniques were used. The data of Momin et $\mathrm{al}^{20}$ do not support the perception that BITA grafting increases wound complications. This trial enfolds a 10 -year period of 95 diabetic patients receiving BITA, and deep sternal wound infection was 1.2 versus $3.2 \%(p=0.36)$.

Interestingly, reoperation for bleeding in the 414 patients of Dorman cohort ${ }^{6}$ was lower in the BITA group (2.4 vs. $3.1 \%$, $p=0.513$ ). Our data do not confirm these results, as frequen- cy of rethoracotomy due to bleeding was significantly higher in the BITA group (3.8 vs. $2.1 \%, p<0.001$ ). This fact might be explainable by the unselected collective in our large series, as we included all patients, for example emergent cases, who were under antiplatelet therapy and, in a not negligible number, patients with obesity (BMI mean was at least 27.2). On the contrary, one of our own previous studies, ${ }^{16}$ consisting of 2,251 patients with extreme obesity (BMI 3050 ), could demonstrate that obesity per se is not a risk factor for increased bleeding or wound-healing complications, but the combination of obesity, diabetes mellitus, and BITA grafting increases the risk for sternal complications. Nevertheless, the blood loss of mean $1,125.5 \pm 850.3 \mathrm{~mL}$ $(p<0.0001)$ in the BITA group seems to be high. In this context, it might be of interest, whether chest-tube output has changed after conversion from pedicled to skeletonized ITA grafts. Other groups likewise describe slightly higher bleeding complications after BITA grafting, ${ }^{12,20}$ commonly associated with a higher number of anastomoses and prolonged X-clamp time. ${ }^{20}$

As expected, perfusion and X-clamp times were significantly prolonged in the BITA group, in our cohort as well as in numerous other publications, and had a significant influence on mortality in the present study. These results compare favorably to other investigations, ${ }^{6}$ which clearly defined prolonged perfusion or X-clamp time as an independent risk factor for increased morbidity or mortality. One cause of prolonged perfusion- and X-clamp time in our series might be the significant higher number of anastomoses within the BITA group. In this context, one will raise up the justified question about a selection bias in our cohort. Doubtlessly, patients with the need for single bypass or, for example, grafts to the $\mathrm{LAD} /$ diagonal branch understandably cannot receive BITA grafting. That means that selection criteria in a predetermined extent are subjected to restrictions depending on vessel status and morphology.

Comparing mortality is another difficult issue. Study designs are varying widely. For example, within the randomized trial of Taggart et al ${ }^{12}$ mortality was $1.2 \%$ for BITA as well as for SITA, therefore much lower than in our series. Around 40\% were performed off-pump, whereas we mostly performed on-pump procedures. Instead of EF, New York Heart Association (NYHA), NY or Canadian Cardiovascular Society (CCS) classification was analyzed and different 
categories for elective/urgent/emergent operations were not presented.

Other series include or exclude emergent operations, a fact that self-evidently must lead to different survival rates. Momin et $\mathrm{al}^{20}$ reported a higher 30-day mortality of 5.0 versus $6.1 \%(p=0.46)$, despite in a comparatively low-aged population (mean 62 years in the BITA group), but included urgent operations in more than $33 \%$. EF was $<30 \%$ in around $10 \%$, more than twofold higher compared with our series, which may easily explain the poorer results. In-hospital mortality within the propensity score-pair-matched collective of diabetic patients published by Dorman et $\mathrm{al}^{6}$ was $4.6 \%$ (SITA) versus 3.1\% (BITA). In the large review of Deo et al, ${ }^{4}$ certainly in diabetic patients, early mortality was $2.5 \%$ in the SITA cohort and $2.3 \%$ in the BITA cohort $(p=0.8)$, therefore analogical to our results. Even, a straight comparability of the numerous studies seems to be difficult, the main focus of the present study is on early postoperative outcome, and we report, to our knowledge, with the experience of 6,476 patients receiving BITA grafting, the largest single-center study concerning this subject.

\section{Limitations}

The retrospective, nonrandomized character might be regarded as a substantial limitation of the present study. Changes of surgical strategies, concerning ITA harvesting lead to a "historical bias." The fact that most of the patients (from 1996 until the year 2010) received pedicled in situ grafts, but only a small number (from the year 2010 to 2012) received skeletonized T-grafts, must result in subgroups, which are hard to compare. Therefore, these results are of a less meaningful statistic power, restricted clinical relevance, and limited validity.

The within the absolute values slight, but nonnegligible bias concerning statistically significant differences in terms of age, BMI, EF, and elective versus emergent cases between both groups might be considered as a result of the large number of patients.

\section{Conclusion}

CABG using BITA can be performed routinely in large patient cohorts with good clinical results and low mortality. Compared with SITA grafting, bleeding complications were enhanced. Prolonged duration of surgery, advanced age, emergent operations, BITA grafting, and obesity could be identified as predictors for sternal instabilities. Sternal wound infections were associated with duration of cardiopulmonary bypass, but nor BITA grafting per se, neither obesity had any influence on sternal wound infections. Number of sternal instabilities was higher in the subgroup receiving skeletonized BITA T-grafts compared with those with pedicled in situ BITA grafts. Pedicled BITA grafting plus diabetes was associated with a higher incidence of sternal instabilities than pedicled BITA grafting without diabetes. Advanced age, $\mathrm{EF}<30 \%$, duration of surgery, prolonged bypass, and X-clamp time plus emergency oper- ation status were independent risk factors for increased 30-day mortality.

\section{Acknowledgments}

The first two authors (O.D. and L.G.) contributed equally to this article. O.D. performed the statistics and evaluation. $\mathrm{L}$. G. prepared the setting, content of the work, and wrote the article.

\section{References}

1 Taggart DP, D'Amico R, Altman DG. Effect of arterial revascularisation on survival: a systematic review of studies comparing bilateral and single internal mammary arteries. Lancet 2001; 358(9285):870-875

2 Rizzoli G, Schiavon L, Bellini P. Does the use of bilateral internal mammary artery (IMA) grafts provide incremental benefit relative to the use of a single IMA graft? A meta-analysis approach. Eur J Cardiothorac Surg 2002;22(5):781-786

3 Kurlansky PA, Traad EA, Dorman MJ, Galbut DL, Zucker M, Ebra G. Thirty-year follow-up defines survival benefit for second internal mammary artery in propensity-matched groups. Ann Thorac Surg 2010;90(1):101-108

4 Deo SV, Shah IK, Dunlay SM, et al. Bilateral internal thoracic artery harvest and deep sternal wound infection in diabetic patients. Ann Thorac Surg 2013;95(3):862-869

5 Choo SJ, Lee SK, Chung SW, et al. Does bilateral pedicle internal thoracic artery harvest increase the risk of mediastinitis? Yonsei Med J 2009;50(1):78-82

6 Dorman MJ, Kurlansky PA, Traad EA, Galbut DL, Zucker M, Ebra G. Bilateral internal mammary artery grafting enhances survival in diabetic patients: a 30-year follow-up of propensity scorematched cohorts. Circulation 2012;126(25):2935-2942

7 Lytle BW, Loop FD. Superiority of bilateral internal thoracic artery grafting: it's been a long time comin'. Circulation 2001;104(18): 2152-2154

8 Rubens FD, Boodhwani M. Skeletonization of the internal thoracic artery for coronary artery bypass grafting. Curr Opin Cardiol 2009; 24(6):559-566

9 Gansera B, Schmidtler F, Angelis I, Kiask T, Kemkes BM, Botzenhardt F. Patency of internal thoracic artery compared to vein grafts - postoperative angiographic findings in 1189 symptomatic patients in 12 years. Thorac Cardiovasc Surg 2007;55(7): 412-417

10 Bridgewater B. Cardiac registers: the adult cardiac surgery register. The Society for Cardiothoracic Adult Cardiac Surgery Database. Heart 2010;96:1441-1443

11 Tabata M, Grab JD, Khalpey Z, et al. Prevalence and variability of internal mammary artery graft use in contemporary multivessel coronary artery bypass surgery. Circulation 2009;120:935-940

12 Taggart DP, Lees B, Gray A, Altman DG, Flather M, Channon K. ART Investigators. A randomized trial to compare survival following bilateral versus single internal mammary grafting in coronary revascularization. Trials 2006;7:7-17

13 De Paulis R, de Notaris S, Scaffa R, et al. The effect of bilateral internal thoracic artery harvesting on superficial and deep sternal infection: The role of skeletonization. J Thorac Cardiovasc Surg 2005;129(3):536-543

14 Gansera B, Günzinger R, Angelis I, Eichinger W, Neumaier-Prauser $\mathrm{P}$, Kemkes BM. End of the millenium- end of the single thoracic artery graft. Two thoracic arteries- standard for the next millenium? Early clinical results and analysis of risk factors in 1487 patients with bilateral internal thoracic artery grafts. Thorac Cardiovasc Surg 2001;49:10-15 
194 Does Bilateral ITA Grafting Increase Perioperative Complications? Deutsch et al.

15 Gansera B, Schmidtler F, Gillrath G, et al. Does bilateral ITA grafting increase perioperative complications? Outcome of 4462 patients with bilateral versus 4204 patients with single ITA bypass. Eur J Cardiothorac Surg 2006;30(2):318-323

16 Syrakas CA, Neumaier-Prauser P, Angelis I, Kiask T, Kemkes BM, Gansera B. Is extreme obesity a risk factor for increased in-hospital mortality and postoperative morbidity after cardiac surgery? Results of 2251 obese patients with BMI of 30 to 50. Thorac Cardiovasc Surg 2007;55(8):491-493

17 Kamiya H, Akhyari P, Martens A, Karck M, Haverich A, Lichtenberg A. Sternal microcirculation after skeletonized versus pedicled harvesting of the internal thoracic artery: a randomized study. J Thorac Cardiovasc Surg 2008;135(1):32-37
18 Boodhwani M, Lam BK, Nathan HJ, et al. Skeletonized internal thoracic artery harvest reduces pain and dysesthesia and improves sternal perfusion after coronary artery bypass surgery: a randomized, double-blind, within-patient comparison. Circulation 2006; 114(8):766-773

19 Toumpoulis IK, Theakos N, Dunning J. Does bilateral internal thoracic artery harvest increase the risk of mediastinitis? Interact Cardiovasc Thorac Surg 2007;6(6): 787-791

20 Momin AU, Deshpande R, Potts J, et al. Incidence of sternal infection in diabetic patients undergoing bilateral internal thoracic artery grafting. Ann Thorac Surg 2005;80(5):1765-1772, discussion 1772 